\title{
Characterization of paucibacillary ileal lesions in sheep with subclinical active infection by Mycobacterium avium subsp. paratuberculosis
}

\author{
Salvatore Pisanu ${ }^{1 \dagger}$, Tiziana Cubeddu ${ }^{2 \dagger}$, Carla Cacciotto ${ }^{1}$, Ylenia Pilicchi ${ }^{2}$, Daniela Pagnozzi ${ }^{1}$, Sergio Uzzau ${ }^{1,3}$, \\ Stefano Rocca ${ }^{2}$ and Maria Filippa Addis ${ }^{1,4^{*}}$ (I)
}

\begin{abstract}
Paratuberculosis (PTB) or Johne's disease is a contagious enteritis of ruminants caused by Mycobacterium avium subsp. paratuberculosis (MAP). Ovine PTB is less understood than bovine PTB, especially concerning paucibacillary infection and its evolution into clinical disease. We combined shotgun proteomics, histopathology and immunohistochemistry for the characterization of ileal tissues collected from seven asymptomatic sheep negative to serum ELISA, positive to feces and tissue MAP IS900 and F57 PCR, histologically classified as paucibacillary, actively infected, together with 3 MAP-free controls (K). Following shotgun proteomics with label-free quantitation and differential analysis, 96 proteins were significantly changed in PTB vs K, and were mostly involved in immune defense processes and in the macrophage-MAP interaction. Principal component analysis (PCA) of protein abundances highlighted two PTB sample clusters, PTB1 and PTB2, indicating a dichotomy in their proteomic profiles. This was in line with the PCA of histopathology data and was related to features of type 2 (PTB1) and type 3a (PTB2) lesions, respectively. PTB2 proteomes differed more than PTB1 proteomes from K: 43 proteins changed significantly only in PTB2 and 11 only in PTB1. The differential proteins cathelicidin, haptoglobin, S100A8 and S100A9 were evaluated by immunohistochemistry. K tissues were negative to cathelicidin and haptoglobin and sparsely positive to S100A8 and S100A9. PTB tissues were positive to all four proteins, with significantly more cells in PTB2 than in PTB1. In conclusion, we described several pathways altered in paucibacillary PTB, highlighted some proteomic differences among paucibacillary PTB cases, and identified potential markers for disease understanding, staging, and detection.
\end{abstract}

\section{Introduction}

Paratuberculosis (PTB) or Johne's disease is a chronic, contagious enteritis of ruminants caused by Mycobacterium avium subspecies paratuberculosis (MAP). PTB is especially relevant in farmed ruminants [1-4] for the economic consequences caused by increase in mortality, decrease in milk production, and weight loss $[5,6]$. In addition, viable MAP can be found in pasteurized milk and milk products with a potential risk of zoonotic transmission [7-9].

\footnotetext{
*Correspondence: filippa.addis@unimi.it

†Salvatore Pisanu and Tiziana Cubeddu contributed equally to this work

${ }^{4}$ Dipartimento di Medicina Veterinaria, Università degli Studi di Milano,

Via Celoria 10, 20133 Milan, Italy

Full list of author information is available at the end of the article
}

MAP and its role in PTB have been the subject of numerous studies on disease progression and evolution in cattle. Our knowledge in this respect has increased considerably, but some aspects remain unclear also in this species, and more effective tools for disease diagnosis and control are still needed [10]. MAP transmission can occur by the fecal-oral route, in utero, and by ingestion of contaminated colostrum or milk [10-15]. Once the bacterium reaches the intestine, it is taken up by $M$ cells and translocated across the intestinal mucosa, where it is internalized by naive macrophages and can lead to persistent infection [16]. In cattle, the disease typically goes from an early subclinical, paucibacillary phase to a later multibacillary phase with severe clinical manifestations of the disease that include wasting and profuse, watery diarrhea [10]. In sheep, PTB is more insidious and

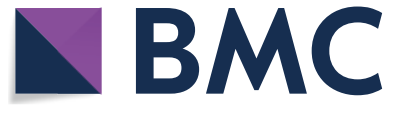

(c) The Author(s) 2018. This article is distributed under the terms of the Creative Commons Attribution 4.0 International License (http://creativecommons.org/licenses/by/4.0/), which permits unrestricted use, distribution, and reproduction in any medium, provided you give appropriate credit to the original author(s) and the source, provide a link to the Creative Commons license, and indicate if changes were made. The Creative Commons Public Domain Dedication waiver (http://creativecommons.org/ publicdomain/zero/1.0/) applies to the data made available in this article, unless otherwise stated. 
classification is less clearly defined [2, 17], leading to a great underestimation of its worldwide diffusion. According to several authors, the largest number of sheep in an affected flock are infected but asymptomatic [18, 19]. These can either have a latent infection, encompassing the presence of MAP in tissues without signs of disease (subclinical infection), or an active infection, in which histological signs of the disease can be observed (subclinical disease) [20, 21]. A histological scoring system [22] classifies these signs into mild lesions represented by small focal granulomata of epithelioid cells limited to the Peyer patches (type 1) or extending to the adjacent mucosa (type 2), and more severe lesions with a multifocal cellular infiltration in mucosal areas not associated with lymphoid tissues and extending into the submucosa, with thickening of the mucosa and atrophy of villi (type $3 a)$. According to Pérez and coworkers [22], symptomatic animals with the end-point disease (clinical disease) present two different types of lesion, lepromatous (type $3 \mathrm{~b}$ ) or tuberculoid (type 3c). Based on the degree of colonization, lesions can also be classified into paucibacillary, with few or no acid-fast bacilli (AFB), and multibacillary, with abundant AFB. Type 1, 2 and 3c lesions are paucibacillary, while type $3 \mathrm{~b}$ are multibacillary. Type 3a lesions are mainly paucibacillary, but multibacillary patterns can also be present, indicating that a crucial "transition stage" may occur in animals with this type of lesions [22]. Actively infected sheep with the subclinical disease can either remain such for their whole life, acting as MAP reservoirs and shedders, or develop clinical disease by showing either paucibacillary (3c) or multibacillary (3b) lesions. At present, factors, pathways, stages and dynamics of disease progression are not completely understood [20], and the best diagnostic approach remains postmortem evaluation with histopathology image analysis, which represents the best indicator to confirm PTB and define its stage $[1,2,23,24]$.

The availability of detailed information on the proteomic alterations introduced in ovine ileal tissues by the subclinical, paucibacillary, active MAP infection would provide novel information for understanding disease mechanisms, discover protein markers with potential for disease staging and, possibly, indicate host proteins that may be shed and detected in feces in vivo. This would also help experimental infection studies aimed at understanding PTB progression to clinical disease. Currently, however, proteomic information on MAP-infected tissues is limited to a preliminary study recently published by our research group and describing the changes occurring in the ileum of sheep with multibacillary, clinical PTB [25].

In this study, we combined histopathology, proteomics, and immunohistochemistry for the characterization of paucibacillary MAP lesions found in actively infected, subclinical sheep. Ileal tissues of asymptomatic, serum ELISA-negative, feces and tissue PCR-positive sheep were subjected to histopathological analysis and those classified as paucibacillary PTB were analyzed by shotgun proteomics in comparison to MAP-free controls. Differential proteins were investigated for host pathways activated during infection. Finally, proteins of interest were evaluated by immunohistochemistry in MAPinfected tissues and in MAP-free controls.

\section{Materials and methods}

\section{Animals and tissues}

Sheep ileal tissues used for the study belonged to a MAPpositive flock of Sarda sheep $(N=174)$. The flock was monitored by the farm veterinarian under an owner voluntary basis by clinical examination, evaluation of PTB symptoms, serological screening by ELISA for presence of anti-MAP antibodies in serum (IDEXX Laboratories, Inc., Westbrook, MA, USA), and IS900 and F57 PCR for presence of MAP in feces, as described previously [25]. Out of 174 sheep, 21 were both ELISA and PCRpositive, 20 were ELISA-positive and PCR-negative, and 15 were ELISA-negative and PCR-positive. The latter 15 were identified as those most probably affected by paucibacillary paraTBC. At routine slaughtering, the intestinal packages belonging to these 15 sheep (all females between 3 and 4 years of age) were retrieved at the slaughterhouse and brought to the Department of Veterinary Medicine at the University of Sassari for gross pathological anatomy examination. Separate aliquots of tissue from the proximal, intermediate, and distal ileum $(N=45$ tissue samples) were collected from each sheep. Matched tissue aliquots were frozen at $-80{ }^{\circ} \mathrm{C}$ or formalin-fixed and paraffin embedded for downstream molecular and histopathological characterization.

\section{Histopathological analysis and molecular characterization of ileal lesions}

Three micrometre sections from paraffin-embedded tissue blocks from each ileal tract were subjected to haematoxylin-eosin and Ziehl-Neelsen (ZN) staining and examined to confirm presence of MAP and associated lesions. PCR was carried out on all 45 frozen tissues samples for confirmation of MAP infection, as described previously [25]. Briefly, DNA was isolated with the DNeasy ${ }^{\circledR}$ Blood and Tissue kit (Qiagen, Hilden, Germany), and tested for presence of the MAP specific sequences IS900 and $\mathrm{F} 57$ by qualitative PCR. The MAP type was also characterized by IS1311, RFLP, and sequencing, as described previously [25, 26]. All 15 tested animals carried the sheep MAP strain (S). FFPE tissue sections obtained from the proximal, intermediate, and distal ileum of the 15 ELISA-negative, PCR-positive sheep ( $N=45$ tissue 
samples) were evaluated by histopathological analysis. Out of these 15 sheep, 7 showed histopathological lesions compatible with paucibacillary paraTBC and were selected for proteomic analysis (Additional file 1). Negative control tissues $(\mathrm{K})$ were obtained from three sheep of a certified MAP-free flock. K sheep were negative to serum ELISA and feces PCR. Their intestinal tissues were negative to PCR, microscopical evaluation and ZiehlNeelsen staining, and showed normal anatomy and histology.

\section{Tissue processing for protein extraction and shotgun proteomic analysis}

Tissue sample preparation was carried out as previously described [25]. Briefly, $100 \mathrm{mg}$ of tissue from the distal ileum of the 7 PTB and $3 \mathrm{~K}$ sheep ( $N=10$ tissue samples) was minced with a sterile knife, placed in Eppendorf safelock tubes (Eppendorf, Hamburg, Germany), immersed in extraction buffer and subjected to homogenization in a TissueLyser mechanical homogenizer (Qiagen, Hilden, Germany) followed by three cycles of sonication and freeze-thawing. Then, the extract was clarified by centrifugation, subjected to nucleic acid digestion, and protein concentration was determined. Extracts and residual pellets $(N=20)$ were processed by filter-aided sample preparation (FASP). Briefly, protein samples were subjected to reduction, alkylation, and trypsin digestion on Amicon Ultra- 0.5 centrifugal filter units with Ultracel-10 membrane (Millipore, Billerica, MA, USA) to obtain sample digests for shotgun proteomic analysis. Peptide concentration of digests was determined by measuring absorbance at $280 \mathrm{~nm}$ with a NanoDrop $2000 \mathrm{spec}-$ trophotometer (Thermo Scientific, San Jose, CA, USA) using MassPREP E. coli Digest Standard (Waters, Milford, MA, USA) to create a calibration curve.

\section{Shotgun proteomic analysis of peptides}

All peptide mixtures were analyzed by liquid chromatography-tandem mass spectrometry (LC-MS/MS) in duplicate runs (two technical replicates for each peptide mixture) on a Q-Exactive interfaced with an UltiMate 3000 RSLCnanoLC system (Thermo Scientific, San Jose, CA, USA), as described previously [27]. Four microgram of each peptide mixture were concentrated and washed onto a trapping precolumn (Acclaim PepMap C18, $75 \mu \mathrm{m} \times 2 \mathrm{~cm}$ nanoViper, $3 \mu \mathrm{m}, 100 \AA$, Thermo Scientific) and fractionated on a C18 RP column (Acclaim PepMap RSLC C18, $75 \mu \mathrm{m} \times 50 \mathrm{~cm}$ nanoViper, $2 \mu \mathrm{m}$, $100 \AA$, Thermo Scientific) at a flow rate of $250 \mathrm{~nL} / \mathrm{min}$ using a linear gradient of $245 \mathrm{~min}$ from 5 to $37.5 \%$ eluent B ( $0.1 \%$ formic acid in $80 \%$ acetonitrile) in eluent A ( $0.1 \%$ formic acid). Fragmentation occurred by higher energy collisional dissociation (HCD) and nitrogen as the collision gas. Proteome Discoverer (version 1.4; Thermo Scientific, Bremen, Germany) was used for protein identification using Sequest-HT as search engine. Each MS/ MS spectrum was analyzed as follows. Database: Bos taurus, Ovis aries, and Mycobacterium avium downloaded from UniProtKB/Swiss-Prot (release 2017 06); enzyme: trypsin, with two missed cleavages allowed; precursor mass tolerance: $10 \mathrm{ppm}$; MS/MS tolerance: $0.02 \mathrm{Da}$; charge states: $+2,+3$, and +4 ; cysteine carbamidomethylation as static modification and methionine oxidation as dynamic modifications. The percolator algorithm $[28,29]$ was used for assessing the significance of protein identification $(P<0.01)$ and for peptide validation (false discovery rate, FDR, $<0.01 \%$ ) $[28,30]$. Only rank 1 peptides and only proteins identified with at least two peptides and two spectral counts were considered. Peptide and protein grouping according to the Proteome Discoverer's algorithm were allowed, applying the strict maximum parsimony principle. The protein list for each intestinal sample was built up by merging the data from the LC-MS/MS runs of the protein extract and of the residual pellet, generating 10 protein identification lists ( 1 for each sheep sample). For proteins having more than one entry, only those with the highest number of unique peptides and spectral counts $(\mathrm{SpC})$ were selected for downstream analyses.

\section{Principal component analysis and hierarchical clustering of samples}

Principal component analysis (PCA) and hierarchical clustering of samples according to proteomic results were carried out based on the normalized spectral abundance factor (NSAF) values of all identified proteins, obtained according to Old et al. [31], as an indicator of protein abundance [32]. PCA and hierarchical clustering of samples according to histopathological results were carried out based on the scores generated upon detailed histological assessment by two observers grading from 0 (absence of feature) to 3 (maximum degree of feature) and reported in Additional file 1. Data analysis was carried out with Perseus (v.1.6.0.7).

\section{Differential proteomic analysis}

To estimate protein abundance and to compare the levels of the same protein among sample groups, a spectral counting approach was applied as described by Old et al. [31] and Zybailov et al. [33]. The $\mathrm{R}_{\mathrm{SC}}$, that is the $\log _{2}$ ratio of protein abundances between two experimental groups, was calculated as described previously [34] and expressed as fold change (FC) [25]. Statistical significance of differences in protein abundance was assessed by the beta-binomial test with FDR correction by BenjaminiHochberg [35, 36]. Only proteins with $\mathrm{FC} \geq 2$ or $\leq-2$, 
with a $p$-value $\leq 0.05$ and present in at least two samples of each group being compared were considered significant.

\section{STRING analysis}

To investigate the biological role of differential proteins, their functional association at a system level [37] was assessed by performing a knowledge-based protein-protein interaction network analysis by means of the biological interface and web resource STRING (version 10.5) after replacing all Ovis aries UniProt IDs with the corresponding Bos taurus UniProt IDs. Specifically, KEGG enrichment analysis was aimed at mapping the differential proteins in biological pathways, while gene ontology (GO) analysis was aimed at mapping them into biological processes (BP), molecular functions (MF), and cellular components $(\mathrm{CC})$.

\section{Immunohistochemistry}

Immunohistochemistry (IHC) was carried out as described previously [38]. Antibodies and dilutions were as follows: rabbit anti-CAMP (Sigma-Aldrich), 1:1500; rabbit anti-S100A8 (Sigma-Aldrich), 1:1000; rabbit antihaptoglobin (Thermo Fisher Scientific), 1:100; rabbit antiS100A9 (Sigma-Aldrich), 1:1000. Signal evaluation was carried out by counting positive cells in 10 random fields at $200 \times$ magnification (PC). Statistical analysis of IHC results was carried out with GraphPad Prism version 5.03 for Windows (GraphPad Software, La Jolla, CA). According to the Shapiro-Wilk normality test the data followed a non-normal distribution, and a nonparametric MannWhitney U-test was therefore applied.

\section{Results}

Shotgun proteomic results, principal component analysis, and hierarchical clustering

A total of 2350 and 2292 proteins were identified in PTB and in K samples, respectively. Details on proteins, peptides, PSMs and search inputs are reported in Additional files 2 and 3. PCA and hierarchical clustering based on protein abundance values (NSAFs as reported in Additional file 3) generated three main clusters: one including all K samples, one including three PTB samples (P4, P6, and P7) and one including four PTB samples (P1, P2, P3, and P5) (Figures 1A and B). K and PTB1 were separated from PTB2 by the first component (16.4\%), while $\mathrm{K}$ was separated from PTB1 by the second component (11.5\%). PCA and hierarchical clustering based on a detailed histopathological analysis with grading scores (Additional file 1) produced similar sample clusters: one including $K$ samples, one including $\mathrm{P} 4, \mathrm{P} 7$, and $\mathrm{P} 6$, and one including P1, P2, P3, and P5 (Figures $1 \mathrm{C}$ and D). $\mathrm{K}$ and PTB1 were separated from PTB2 by the first component (64.5\%), while K was separated from PTB1 by the second component (14.3\%). Therefore, PCA carried out on histopathological classification mirrored proteomic data and confirmed the PTB1/PTB2 clustering, characterized by a lower divergence of three samples (designated as PTB1 cluster) and a higher divergence of the other four (designated as PTB2 cluster) from controls (K). Based on histopathological observations, PTB1 samples presented features more compatible with the definition of type 2 lesions, while PTB2 samples were more compatible with the definition of type 3a lesions (Additional file 1).

\section{Differential proteomic analysis}

In view of the results obtained by PCA and hierarchical clustering of both proteomics and histopathology results, the differential proteomic analysis was carried out by comparing: (i) all PTB samples vs K; (ii) only PTB1 samples vs K; and (iii) only PTB2 samples vs K. Results are reported in Table 1 and in Additional file 3.

A total of 96 proteins showed statistically significant differences (Table 1). Of these, 69 were higher and 27 were lower in PTB vs K, respectively. Of the 69 increased proteins, 33 were statistically significant in all PTB samples, 6 only in PTB1, and 30 only in PTB2. Of the 27 decreased proteins, 9 were statistically significant in all PTB samples, 5 only in PTB1, and 13 only in PTB2 (Table 1). The higher number of differential proteins detected in PTB2 samples indicates that these differ more than PTB1 samples from $K$, and suggests the presence of two different levels of tissue involvement in the PTB sample set. Eleven proteins were identified in the MAP database and included in the differential analysis (Additional file 3). Among them, only chaperone protein HtpG passed the thresholds for FC value and statistical significance (Table 1).

\section{KEGG enrichment and gene ontology analysis of differential proteins}

Differential proteins were evaluated for protein networks by STRING. KEGG enrichment and GO results are summarized in Additional file 4.

For the 69 proteins increased in all PTB samples, KEGG enrichment (Figure 2A) highlighted three main networks. The first network was phagosome $(P=5.97 \mathrm{E}-06)$, including V-type proton ATPase catalytic subunit A (ATP6V1A), V-type proton ATPase subunit B (ATP6V1B2), V-type proton ATPase subunit H (ATP6V1H), cathepsin S (CTSS), integrin beta-2 (ITGB2), neutrophil cytosol factor 2 (NCF2), rasrelated protein Rab-5A (RAB5A), and protein transport protein Sec61 subunit gamma (SEC61G) (Figure 2B). The second network was tuberculosis $(P=1.03 \mathrm{E}-03)$, including ATP6V1H, cathelicidin 1 (CATHL1A), CTSS, 

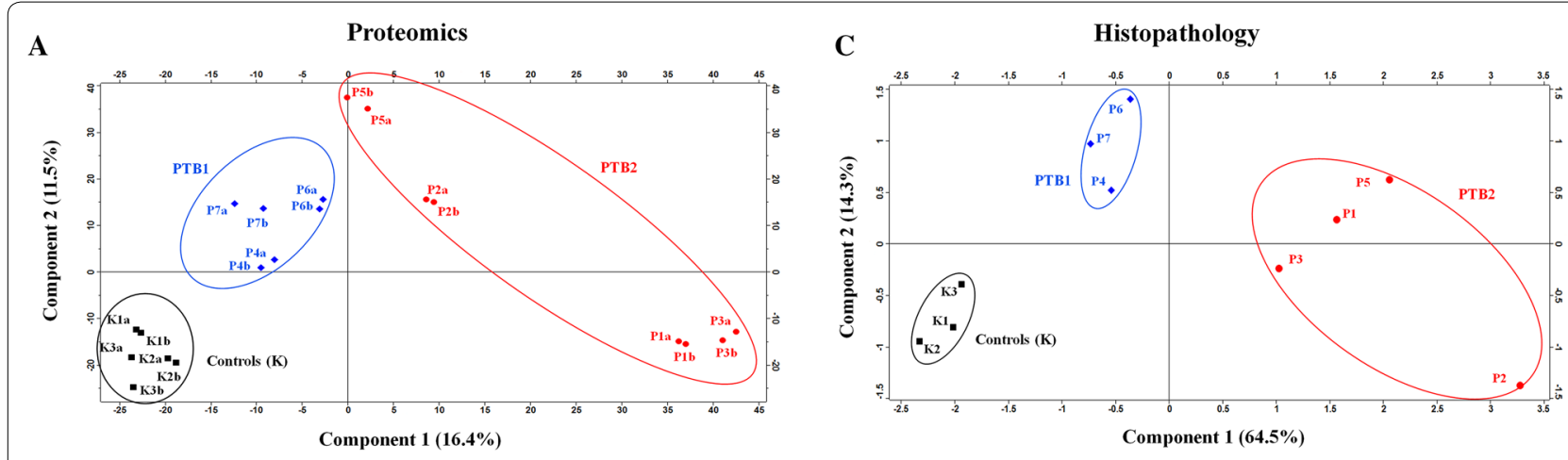

B

D
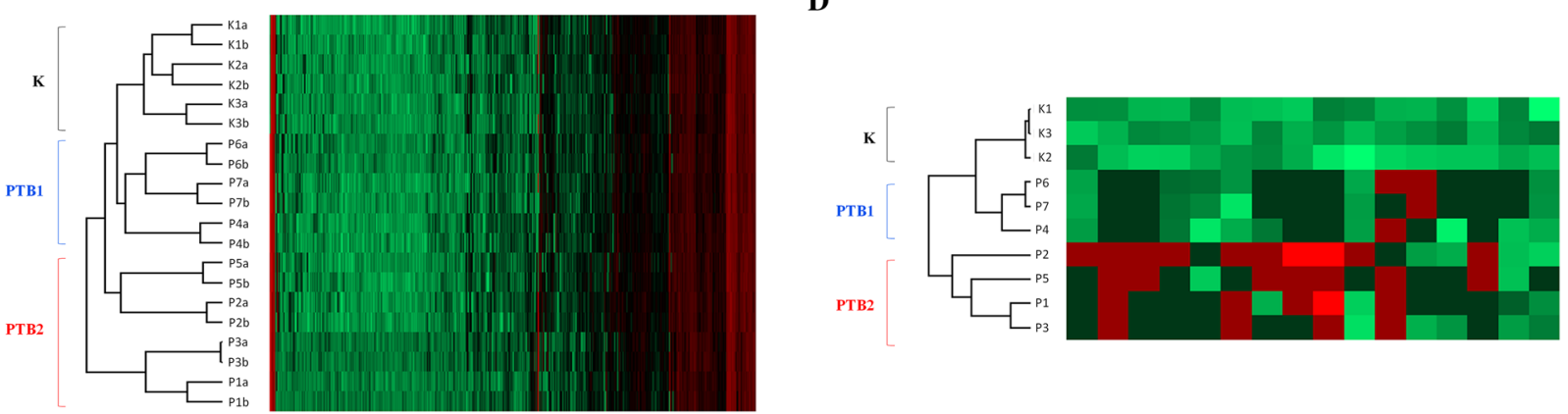

Figure 1 Clustering of samples according to protein abundance values and histopathological features. The two panels show the PCA clustering on top and the hierarchical clustering heatmap on the bottom. Left, clustering based on shotgun proteomics. Right; clustering based on histopathology. Two technical replicates were analyzed in shotgun proteomics experiments, and results are reported separately for the two replicates as a and b, respectively. P indicates paucibacillary samples; $\mathrm{K}$ indicates control samples. A Results of PCA based on protein abundance values in terms of normalized spectrum abundance factors (NSAFs). B Hierarchical clustering of samples based on NSAFs. Protein identities and abundances are reported in Additional file 3. C Results of PCA based on histopathological grading. D Hierarchical clustering of samples based on histopathological grading. Parameters and scores are detailed in Additional file 1.

ITGB2, myeloid differentiation primary response protein MyD88 (MYD88), and RAB5A (Figure 2C). And the third network was lysosome $(P=2.82 \mathrm{E}-02)$, including acid ceramidase (ASAH1), ATP6V1H, CTSS, and IGF2R (Figure 2D). Figures $2 B, C$ and $D$ report the relative abundance (NSAF) of the proteins that describe the pathways. Eight out of these 11 proteins (ATP6V1A, ATP6V1B2, ATP6V1H, CTSS, IGF2R, ITGB2, NCF2, and RAB5A) were significantly higher only in PTB2. Only 4 proteins (ASAH1, CATHL1, MYD88, and SEC61G) were higher in both PTB1 and PTB2 clusters and in all PTB samples analyzed together. Among these, MYD88 and SEC61G were similar in the two PTB clusters, while CATHL1 and ASAH1 were more abundant in PTB2.

GO analysis (Figure 3A) highlighted 5 main networks. The first network was defense response $(P=8.65 \mathrm{E}-05)$ with CATHL1A, cathelicidin 2 (CATHL2), scavenger receptor cysteine-rich type 1 protein M130 (CD163), chitinase-3-like protein 1 (CHI3L1), histone H2B type 1 (H2B), haptoglobin (HP), MYD88, protein S100-A8 (S100A8), and serum amyloid A protein (SAA2)
(Figure $3 \mathrm{~B})$. The second network was inflammatory response $(P=5.61 \mathrm{E}-04)$ with $\mathrm{CD} 163, \mathrm{CHI} 3 \mathrm{~L} 1, \mathrm{HP}$, MYD88, S100A8, and SAA2 (Figure 3C). The third network was acute phase response $(P=3.47 \mathrm{E}-03)$ with CD163, HP, MYD88, and SAA2 (Figure 3D). The fourth network was cell chemotaxis $(P=2.25 \mathrm{E}-03)$ with ITGB2, ras-related protein Rab-13 (RAB13), S100A8, and SAA2 (Figure 3E). Finally, the fifth network was apoptotic process $(P=2.12 \mathrm{E}-02)$ with caspase-13 (CASP4 or CASP13), CHI3L1, deoxyribonuclease-1 (DNASE1), ERO1-like protein alpha (ERO1L or ERO1A), notchless protein homolog 1 (NLE1), and S100A8 (Figure 3F). These are described by a total of 15 proteins, 11 of which are significant only in the PTB2 cluster. As evidenced by KEGG enrichment analysis and GO analysis, proteins higher in PTB2 were likely associated with a more marked tissue alteration when compared to PTB1 and were characterized by numerous processes associated with the presence of MAP.

The 27 proteins decreased in PTB (Figure 4A) were mainly involved in the networks biological process $(P=3.48 \mathrm{E}-02)$ and metabolic process $(P=3.48 \mathrm{E}-02)$ 
Table 1 Differential proteins in all PTB, PTB1 and PTB2 vs K samples, respectively

\begin{tabular}{|c|c|c|c|c|c|}
\hline Accession & Gene name & Description & All PTB vs $\mathrm{K}$ & PTB1 vs $\mathrm{K}$ & PTB2 vs $\mathrm{K}$ \\
\hline P62808 & $\mathrm{H} 2 \mathrm{~B}$ & Histone H2B type 1 & 138.55 & 159.95 & 122.71 \\
\hline P63048 & UBA52 & Ubiquitin-60S ribosomal protein $L 40$ & 70.26 & 67.05 & 72.67 \\
\hline A0JNJ5 & MYL1 & Myosin light chain $1 / 3$, skeletal muscle isoform & 16.55 & 23.39 & 11.42 \\
\hline Q17QN3 & SNRPN & Small nuclear ribonucleoprotein-associated protein $\mathrm{N}$ & 11.68 & 9.08 & 13.31 \\
\hline A1L595 & KRT17 & Keratin, type I cytoskeletal 17 & 11.29 & $13.98^{b}$ & 9.06 \\
\hline AOAOE2WA25 & $H t p G$ & Chaperone protein HtpG & 8.67 & 5.32 & 11.19 \\
\hline $\mathrm{A} 217 \mathrm{NO}$ & SERPINA3-4 & Serpin A3-4 & 6.70 & 7.62 & 6.05 \\
\hline Q9BE41 & $\mathrm{MYH} 2$ & Myosin-2 & 5.76 & 5.37 & 5.78 \\
\hline P22226 & CATHL1A & Cathelicidin-1 & 5.44 & 3.06 & 7.54 \\
\hline Q29437 & AOCX & Primary amine oxidase, liver isozyme & 5.29 & 5.69 & $4.99^{b}$ \\
\hline Q56JX9 & FABP2 & Fatty acid-binding protein, intestinal & 5.07 & 9.92 & $1.43^{b}$ \\
\hline Q3T104 & SEC61G & Protein transport protein Sec61 subunit gamma & 4.69 & 4.21 & 5.28 \\
\hline Q17QB3 & ASAH1 & Acid ceramidase & 3.75 & 3.11 & 4.17 \\
\hline P19660 & CATHL2 & Cathelicidin-2 & 3.67 & 2.14 & 5.10 \\
\hline Q5E972 & ORMDL2 & ORM1-like protein 2 & 3.28 & 2.69 & 3.73 \\
\hline Q9N0K1 & CD47 & Leukocyte surface antigen CD47 & 2.99 & $1.98^{\mathrm{b}}$ & 3.40 \\
\hline Q0॥G7 & RAB5A & Ras-related protein Rab-5A & 2.89 & $1.81^{\mathrm{b}}$ & 3.70 \\
\hline P61625 & ITGAL & Integrin alpha-L & 2.73 & $-1.17^{b}$ & 4.14 \\
\hline Q1JPB0 & SERPINB1 & Leukocyte elastase inhibitor & 2.64 & $1.28^{\mathrm{b}}$ & 3.72 \\
\hline P85521 & CD163 & Scavenger receptor cysteine-rich type 1 protein M130 & 2.56 & $1.14^{\mathrm{b}}$ & 3.63 \\
\hline Q58DS5 & RAB13 & Ras-related protein Rab-13 & 2.50 & 2.33 & 2.40 \\
\hline Q9BDK2 & AlF1 & Allograft inflammatory factor 1 & 2.49 & $1.13^{b}$ & 3.51 \\
\hline P79106 & PAFAH2 & Platelet-activating factor acetylhydrolase 2 & 2.45 & $2.05^{b}$ & 2.76 \\
\hline P09578 & MT1C & Metallothionein-1C & 2.44 & 2.35 & $2.43^{b}$ \\
\hline P83095 & LACTB & Serine beta-lactamase-like protein LACTB & 2.44 & $1.39^{b}$ & 3.23 \\
\hline Q95JC7 & SLC1A5 & Neutral amino acid transporter B (0) & 2.43 & $2.05^{\mathrm{b}}$ & 2.72 \\
\hline P55156 & MTTP & Microsomal triglyceride transfer protein large subunit & 2.37 & 3.45 & $1.56^{\mathrm{a}}$ \\
\hline Q2YDN6 & RPF2 & Ribosome production factor 2 homolog & 2.37 & $1.45^{\mathrm{b}}$ & 3.06 \\
\hline P00766 & CTRA & Chymotrypsinogen A & 2.21 & -2.76 & 3.60 \\
\hline Q28035 & GSTA1 & Glutathione S-transferase A1 & 2.11 & 3.73 & $-1.11^{\mathrm{a}}$ \\
\hline Q599T9 & MYD88 & Myeloid differentiation primary response protein MyD88 & 2.06 & 2.35 & 2.00 \\
\hline P61955 & SUMO2 & Small ubiquitin-related modifier 2 & 2.04 & $1.94^{\mathrm{b}}$ & 2.12 \\
\hline Q95115 & STAT5A & Signal transducer and activator of transcription $5 \mathrm{~A}$ & 2.04 & $1.66^{b}$ & 2.33 \\
\hline Q3SWY9 & RAB28 & Ras-related protein Rab-28 & $1.73^{b}$ & 2.42 & - \\
\hline Q32L48 & HIST1H2BN & Histone H2B type 1-N & $1.55^{\mathrm{b}}$ & 2.25 & $1.01^{b}$ \\
\hline A7YWK3 & KRT73 & Keratin, type II cytoskeletal 73 & $1.49^{b}$ & 2.24 & $-1.08^{b}$ \\
\hline A2VDL6 & ATP1A2 & Sodium/potassium-transporting ATPase subunit alpha-2 & $1.44^{b}$ & 2.22 & $-1.16^{\mathrm{a}}$ \\
\hline Q2TBP0 & PSMB7 & Proteasome subunit beta type-7 & $1.64^{\mathrm{a}}$ & 2.10 & $1.30^{\mathrm{a}}$ \\
\hline P14568 & ASS1 & Argininosuccinate synthase & $1.40^{\mathrm{a}}$ & 2.05 & $-1.09^{b}$ \\
\hline Q2TBU0 & $H P$ & Haptoglobin & $8.14^{b}$ & - & 13.84 \\
\hline P00639 & DNASE1 & Deoxyribonuclease-1 & $3.97^{b}$ & $-1.57^{b}$ & 6.48 \\
\hline P30922 & CHI3L1 & Chitinase-3-like protein 1 & $3.67^{b}$ & $1.16^{\mathrm{b}}$ & 5.80 \\
\hline Q0P5C2 & MTHFD2 & Bifunctional methylenetetrahydrofolate dehydrogenase & $3.04^{b}$ & $1.57^{b}$ & 3.92 \\
\hline Q1LZA3 & ASNS & Asparagine synthetase & $2.44^{b}$ & $1.25^{\mathrm{b}}$ & 3.53 \\
\hline P00760 & TRY1 & Cationic trypsin & $1.92^{\mathrm{a}}$ & $2.33^{b}$ & 3.03 \\
\hline O77775 & NCF2 & Neutrophil cytosol factor 2 & $2.25^{b}$ & $1.20^{\mathrm{b}}$ & 3.03 \\
\hline P08169 & IGF2R & Cation-independent mannose-6-phosphate receptor & $1.11^{\mathrm{b}}$ & $-1.05^{b}$ & 2.99 \\
\hline P28782 & S100A8 & Protein S100-A8 & $1.94^{b}$ & - & 2.89 \\
\hline P32592 & ITGB2 & Integrin beta-2 & $1.86^{\mathrm{b}}$ & $1.20^{\mathrm{b}}$ & 2.64 \\
\hline Q2HJH7 & MEMO1 & Protein MEMO1 & $2.31^{b}$ & $1.85^{\mathrm{b}}$ & 2.62 \\
\hline 075601 & CASP13 & Caspase-13 & $1.75^{\mathrm{a}}$ & $1.01^{\mathrm{a}}$ & 2.60 \\
\hline
\end{tabular}


Table 1 (continued)

\begin{tabular}{|c|c|c|c|c|c|}
\hline Accession & Gene name & Description & All PTB vs $\mathrm{K}$ & PTB1 vs $K$ & PTB2 vs $K$ \\
\hline O77588 & PLOD1 & Procollagen-lysine,2-oxoglutarate 5-dioxygenase 1 & $1.91^{\mathrm{b}}$ & $-1.12^{\mathrm{b}}$ & 2.57 \\
\hline Q5EAD2 & PHGDH & D-3-Phosphoglycerate dehydrogenase & $1.98^{\mathrm{a}}$ & $1.27^{\mathrm{b}}$ & 2.51 \\
\hline A2VDZ9 & VAPB & Vesicle-associated membrane protein-associated protein B & $2.15^{\mathrm{b}}$ & $1.72^{\mathrm{b}}$ & 2.46 \\
\hline P31408 & ATP6V1B2 & V-type proton ATPase subunit B & $1.12^{\mathrm{b}}$ & $1.06^{\mathrm{b}}$ & 2.45 \\
\hline P25326 & CTSS & Cathepsin S & $2.01^{\mathrm{b}}$ & $1.15^{\mathrm{b}}$ & 2.38 \\
\hline A5PJP1 & BLOC1S3 & Biogenesis of lysosome-related organelles complex 1 sub 3 & $1.76^{\mathrm{b}}$ & - & 2.38 \\
\hline Q29RY9 & NPL & $\mathrm{N}$-acetylneuraminate lyase & $1.74^{\mathrm{a}}$ & $1.10^{\mathrm{a}}$ & 2.36 \\
\hline A5PJN2 & ERO1L & ERO1-like protein alpha & $1.72^{\mathrm{b}}$ & $1.06^{\mathrm{b}}$ & 2.30 \\
\hline Q2TBK3 & PLAC9 & Placenta-specific protein 9 & $1.71^{\mathrm{a}}$ & $1.02^{\mathrm{b}}$ & 2.23 \\
\hline P31404 & ATP6V1A & V-type proton ATPase catalytic subunit A & $1.75^{\mathrm{a}}$ & $1.11^{\mathrm{b}}$ & 2.22 \\
\hline Q3ZBI6 & FHL3 & Four and a half LIM domains protein 3 & $1.70^{\mathrm{a}}$ & $1.03^{b}$ & 2.21 \\
\hline Q3SZZO & BRIX1 & Ribosome biogenesis protein BRX1 homolog & $1.88^{\mathrm{b}}$ & $1.47^{\mathrm{b}}$ & 2.18 \\
\hline O46563 & ATP6V1H & V-type proton ATPase subunit $\mathrm{H}$ & $1.62^{\mathrm{b}}$ & $1.11^{\mathrm{b}}$ & 2.16 \\
\hline P35541 & SAA1 & Serum amyloid A protein & $1.41^{\mathrm{b}}$ & - & 2.15 \\
\hline Q17QL5 & TMEM30A & Cell cycle control protein 50A & $1.82^{\mathrm{b}}$ & $1.49^{\mathrm{a}}$ & 2.07 \\
\hline Q865V6 & CAPG & Macrophage-capping protein & $1.56^{\mathrm{b}}$ & $-1.10^{\mathrm{b}}$ & 2.05 \\
\hline Q58D20 & NLE1 & Notchless protein homolog 1 & $1.90^{\mathrm{b}}$ & $1.74^{\mathrm{b}}$ & 2.03 \\
\hline P06868 & PLG & Plasminogen & $1.63^{\mathrm{b}}$ & $1.17^{\mathrm{b}}$ & 2.00 \\
\hline P80931 & MCT1A & Mast cell protease $1 \mathrm{~A}$ & $-1.70^{\mathrm{b}}$ & $1.19^{\mathrm{b}}$ & -7.28 \\
\hline Q6B410 & LYSI & Lysozyme C & $-1.92^{\mathrm{b}}$ & $-1.07^{\mathrm{b}}$ & -4.81 \\
\hline Q3SZX4 & CA3 & Carbonic anhydrase 3 & $-1.74^{\mathrm{b}}$ & $1.03^{b}$ & -4.29 \\
\hline Q7YRZ7 & GZMA & Granzyme A & $-1.76^{\mathrm{a}}$ & $-1.16^{\mathrm{b}}$ & -2.91 \\
\hline P19111 & ALPI & Intestinal-type alkaline phosphatase & $-1.28^{\mathrm{b}}$ & $1.29^{\mathrm{b}}$ & -2.62 \\
\hline A8YXX7 & TFF3 & Trefoil factor 3 & $-1.43^{b}$ & $1.11^{\mathrm{b}}$ & -2.54 \\
\hline Q3T166 & MPTX & Mucosal pentraxin & $-1.01^{\mathrm{a}}$ & $1.77^{\mathrm{b}}$ & -2.52 \\
\hline Q28106 & CNTN1 & Contactin-1 & $-1.40^{\mathrm{b}}$ & $1.12^{\mathrm{b}}$ & -2.43 \\
\hline Q3MHR3 & DYNLL2 & Dynein light chain 2 & $-1.63^{\mathrm{b}}$ & $-1.22^{\mathrm{b}}$ & -2.16 \\
\hline Q5EA62 & FBLN5 & Fibulin-5 & $-1.49^{\mathrm{b}}$ & $-1.05^{\mathrm{b}}$ & -2.16 \\
\hline Q3MHNO & PSMB6 & Proteasome subunit beta type- 6 & $-1.63^{\mathrm{b}}$ & $-1.30^{\mathrm{b}}$ & -2.16 \\
\hline Q3T0Z2 & FABP6 & Gastrotropin & $-1.85^{\mathrm{b}}$ & $-1.65^{\mathrm{b}}$ & -2.05 \\
\hline P31836 & NCAM1 & Neural cell adhesion molecule 1 & $-1.49^{\mathrm{b}}$ & $-1.10^{\mathrm{b}}$ & -2.02 \\
\hline Q2M2T1 & HIST1H2BK & Histone H2B type $1-\mathrm{K}$ & $-1.24^{\mathrm{a}}$ & -3.55 & $1.20^{\mathrm{a}}$ \\
\hline Q3T052 & $\mathrm{ITIH} 4$ & Inter-alpha-trypsin inhibitor heavy chain $\mathrm{H} 4$ & $-0.83^{\mathrm{a}}$ & -2.63 & $1.82^{\mathrm{b}}$ \\
\hline P61823 & RNASE1 & Ribonuclease, pancreatic & $-1.11^{\mathrm{a}}$ & -2.60 & $1.66^{\mathrm{a}}$ \\
\hline Q29RQ9 & ORMDL1 & ORM1-like protein 1 & $-1.59^{\mathrm{b}}$ & -2.25 & $-1.43^{\mathrm{b}}$ \\
\hline $\mathrm{A} 1 \mathrm{~A} 4 \mathrm{Q} 4$ & TMA7 & Translation machinery-associated protein 7 & $-1.00^{\mathrm{a}}$ & -2.23 & $1.41^{\mathrm{b}}$ \\
\hline Q32PH8 & EEF1A2 & Elongation factor 1-alpha 2 & -2.01 & $-1.56^{\mathrm{a}}$ & -2.57 \\
\hline Q01119 & ACTN3 & Alpha-actinin-3 & -2.36 & -2.54 & -2.24 \\
\hline P00978 & IATR & Inter-alpha-trypsin inhibitor & -4.09 & -4.38 & -3.37 \\
\hline Q9BE39 & $\mathrm{MYH7}$ & Myosin-7 & -6.04 & -6.80 & -5.23 \\
\hline Q9BE40 & MYH1 & Myosin-1 & -6.28 & -7.08 & -5.44 \\
\hline O62664 & PTGS1 & Prostaglandin $\mathrm{G} / \mathrm{H}$ synthase 1 & -6.39 & -7.20 & -5.54 \\
\hline Q58DW4 & SNRPB & Small nuclear ribonucleoprotein-associated protein $B^{\prime}$ & -6.81 & -7.66 & -5.90 \\
\hline Q32KN8 & TUBA3 & Tubulin alpha-3 chain & -52.20 & -60.66 & -46.68 \\
\hline Q2HJ86 & TUBA1D & Tubulin alpha-1D chain & -97.29 & -113.10 & -87.02 \\
\hline
\end{tabular}

Differences in abundance are reported as fold changes in the respective sample comparisons. Statistically significant proteins are in bolditalics. The only statistically significant MAP protein is in italics.

In bolditalics: fold change $\leq-2$ or $\geq 2$, beta-binomial test $P \leq 0.05$.

${ }^{a}$ Fold change $\geq-2$ or $\leq 2$, beta-binomial test $P \leq 0.05$

b Any fold change with non-significant beta-binomial test. 


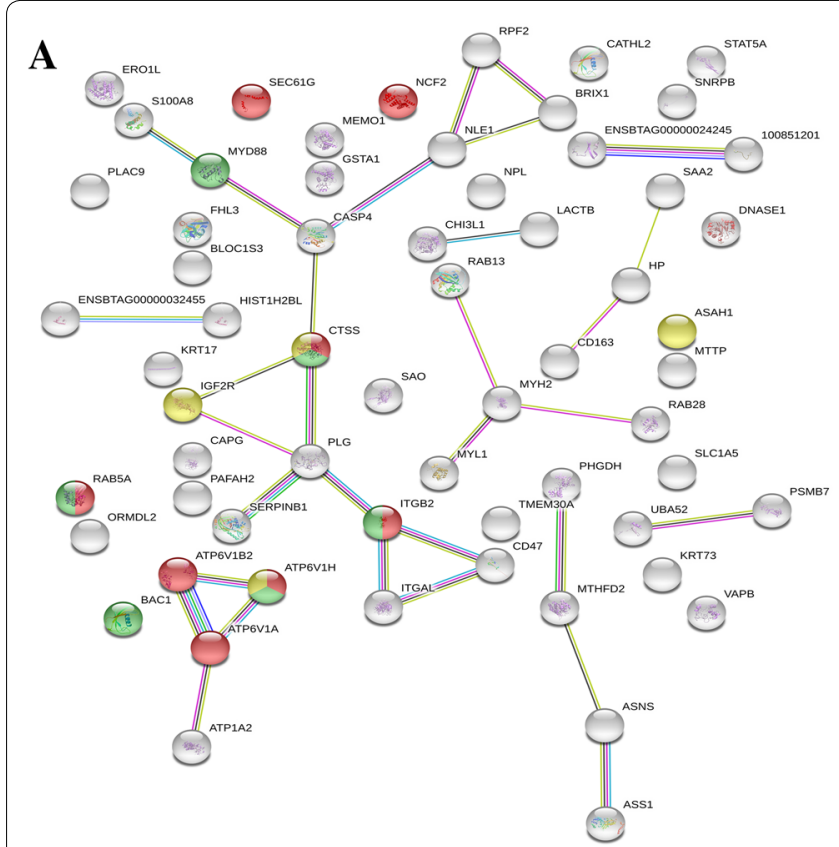

B
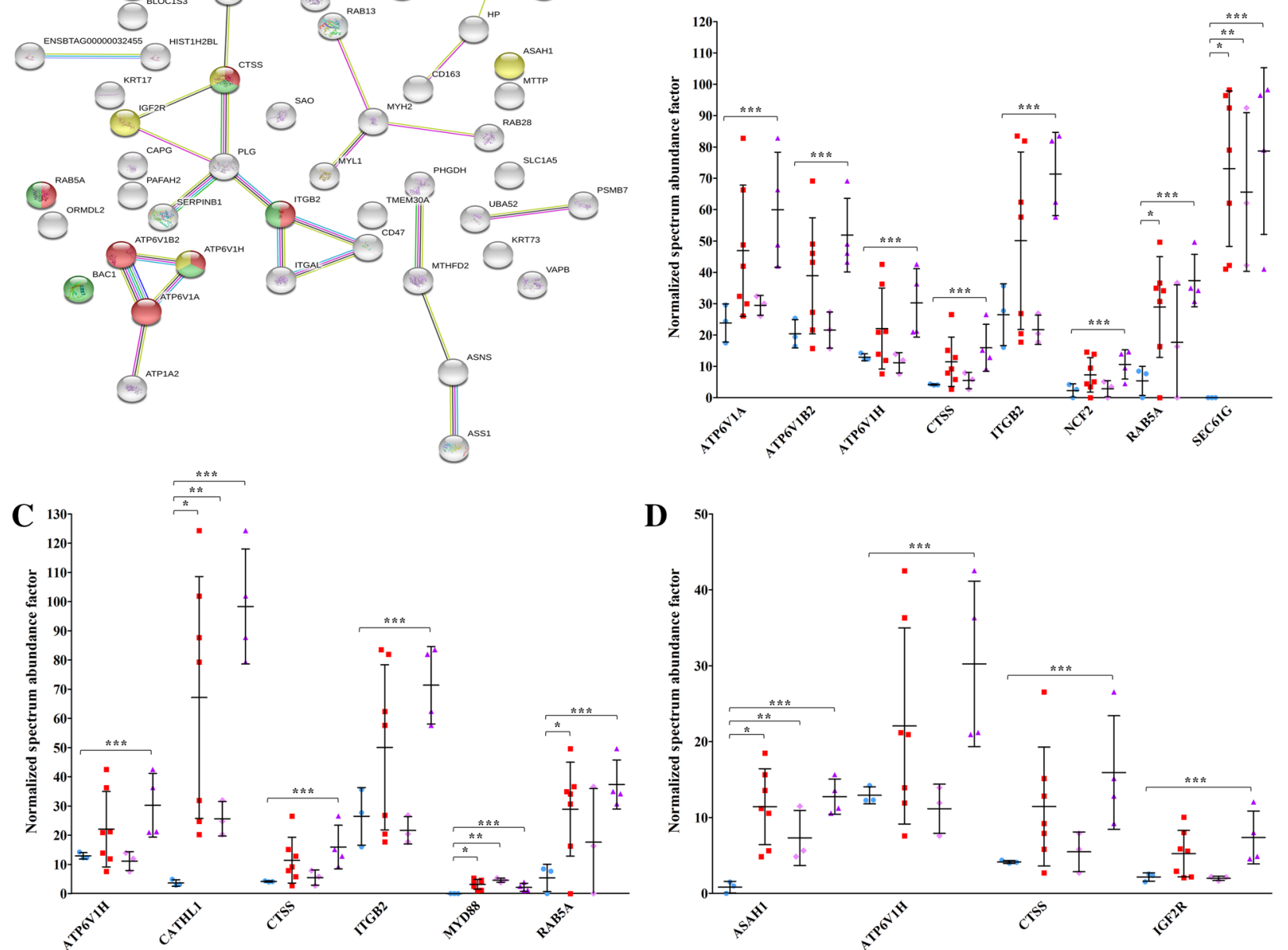

Figure 2 KEGG enrichment analysis of proteins significantly increased in PTB vs K. The figure reports the protein network and the proteins included in each category, with the respective abundance increases in all PTB samples, in PTB1, and in PTB2, respectively. A Protein network according to STRING. Proteins associated with phagosome, lysosome, and tuberculosis are indicated in red, green, and yellow, respectively. Seven different colored lines link nodes and represent seven types of evidence used in predicting associations. Green lines: neighborhood evidence; red lines: presence of fusion evidence; blue lines: co-occurrence evidence; black lines: co-expression evidence; purple lines: experimental evidence; light blue lines: database evidence; yellow lines: text-mining evidence. Plots show the relative abundances of proteins in the phagosome (B), lysosome (C), and tuberculosis (D) pathways. Plots report values obtained in K (sky blue), PTB (red), PTB1 (pink), and PTB2 (purple) samples. Asterisks indicate statistically significant differences between PTB vs K $(*)$, PTB1 vs $K\left(^{* *}\right)$, and PTB2 vs $K\left(^{* * *}\right)$ according to the t-test $(p$ value $\leq 0.05)$. For protein identities corresponding to gene names, please see Table 1.

(Additional file 4). STRING revealed changes associated to cytoskeleton network $(P=1.17 \mathrm{E}-02)$, including dynein light chain 2 (DYNLL2), myosin-1 (MYH1), myosin-7 (MYH7), tubulin alpha-1D chain (TUBA1D), and tubulin alpha-3 chain (TUBA3E) (Figure 4B). These proteins are also found in the networks: myosin complex $(P=6.93 \mathrm{E}-04)$ including DYNLL2, MYH1 and
MYH7, and microtubule $(P=3.05 \mathrm{E}-02)$ with DYNLL2, TUBA1, and TUBA3E.

\section{IHC evaluation of selected differential proteins}

Cathelicidin, haptoglobin, S100A8 and S100A9 were further investigated by IHC to validate proteomic results and to explore their value as potential indicators of 
disease severity or progression (Figure 5), in view of the observed differences in protein levels among samples and of their role in MAP infection and host immunity. Specifically, cathelicidin was selected because two different proteoforms (cathelicidin-1 and cathelicidin-2) were among the top 15 significantly higher proteins in PTB samples (Table 1), and also in consideration of its well-known role in mycobacterial killing [39] and innate immunity [40, 41]. Haptoglobin and S100A8 were selected for being the first and the second protein significantly increased only in PTB2 (Table 1). S100A9 was also assessed for being a subunit of the intestinal inflammation marker calprotectin together with S100A8 [42]. Mean, standard deviation, median, interquartile ranges, and minimum-maximum values of the number of positive cells observed in a $200 \times$ magnification field are reported in Additional file 5 for each marker. As a result, $\mathrm{K}$ samples (Figure 5, first row) were always negative to cathelicidins and haptoglobin while S100A8 and S100A9 showed few scattered signals. Cells positive to all four proteins were readily detectable in PTB samples, with significantly lower numbers in PTB1 (Figure 5, second row) than PTB2 (Figure 5, third row). Cathelicidinpositive cells (Figure 5, first column) were about 30-fold higher in PTB2 (median value 1.00 in PTB1 vs 30.50 in PTB2, $P<0.0001)$ and were morphologically compatible with dendritic cells (DCs, stronger signals) or epithelial cells (weaker signals). Haptoglobin-positive cells (Figure 5, second column) were about 40-fold higher in PTB2 than PTB1 (median value 0.00 in PTB1 vs 41.50 in PTB2, $P<0.0001)$. Haptoglobin was localized exclusively in correspondence of macrophages. S100A8-positive cells (Figure 5, third column) were about threefold higher in PTB2 (median value 6.00 in PTB1 vs 17.00 in PTB2, $P<0.0001$ ). The cell type positive to S100A8 was compatible with Paneth cells for localization and morphology. S100A9positive cells (Figure 5, fourth column) were about sixfold higher in PTB2 (median value 6.00 in PTB1 vs 36.00 in PTB2, $P<0.001$ ). In the case of S100A9, the positive cell type was not clearly recognizable in PTB1, while it was almost exclusively macrophages in PTB2.

\section{Discussion}

Differential shotgun proteomics enables to investigate the changes occurring in the protein makeup of a tissue in a condition of interest, such as in a pathological state against the physiological state. The proteomic approach presents advantages and disadvantages in comparison to gene expression strategies. One advantage is the ability to truly evaluate the extent of protein abundance, going beyond the estimates based on gene expression. In fact, several proteins do not follow a strict relationship with gene transcription but are regulated at translational or post-translational level, as in the case of cathelicidins [38, 43]. Moreover, adding to changes in protein abundance, changes in protein localization can often be revealed including protein capture or release phenomena, provided that histological evaluations are carried out for further investigation or validation. On the other hand, the number of samples in a high-performance shotgun proteomics study is typically limited by analytical throughput and cost issues. In addition, the sensitivity of proteomics is not as high as transcriptomics, and some relevant low-abundance, transient mediators may not be detected, including cytokines.

In this study, the application of shotgun proteomics to paucibacillary MAP-infected sheep ileal tissues (PTB) and matched MAP-free controls (K) highlighted several host proteins and pathways that are altered by MAP upon infection. In addition, proteomic results and histopathological grading revealed the presence of two PTB sample clusters, one with a higher (PTB2) and one with a lower proteomic divergence (PTB1) from $\mathrm{K}$. That is, several proteins associated with MAP infection and with its pathological process changed more intensely in the PTB2 than in the PTB1 sample cluster. This was also reflected by the different abundance of the MAP chaperone protein HtpG in the two clusters, with FC values of 5.32 in PTB1 and 11.19 in PTB2, respectively. Based on histological observations, the PTB1 and PTB2 proteomic profiles might relate to paucibacillary type 2 and type 3a lesions [22], indicating that the different levels of tissue alteration and lesion severity found in sheep with subclinical, active, paucibacillary MAP infection might be associated to specific changes in their proteomic profiles.

According to KEGG enrichment analysis, the differential proteins seen in intestinal tissues of PTB sheep were mainly involved in phagosome formation, lysosome function and tuberculosis. This is due to the MAP strategy of survival within macrophages: impairment of phagosome and lysosome fusion. The mechanism is shared with other mycobacteria including the more intensively investigated M. tuberculosis [10]. Interestingly, most of these proteins changed significantly only in PTB2. Three out of eight proteins of the phagosome pathway were subunits of the V-type proton ATPase complex (V-ATPase). $\mathrm{V}$-ATPase is responsible for phagolysosome acidification. By specifically excluding V-ATPase from this compartment, mycobacteria can survive and multiply within macrophages [10, 44]. Different authors have reported a higher expression of V-ATPase in MAP-infected macrophages as compared to macrophages infected with non-pathogenic mycobacteria [45-47]. This finding is in line with our previous work on multibacillary PTB, where we observed an increase in most V-ATPase subunits. In that work, consistently with a higher MAP load and 

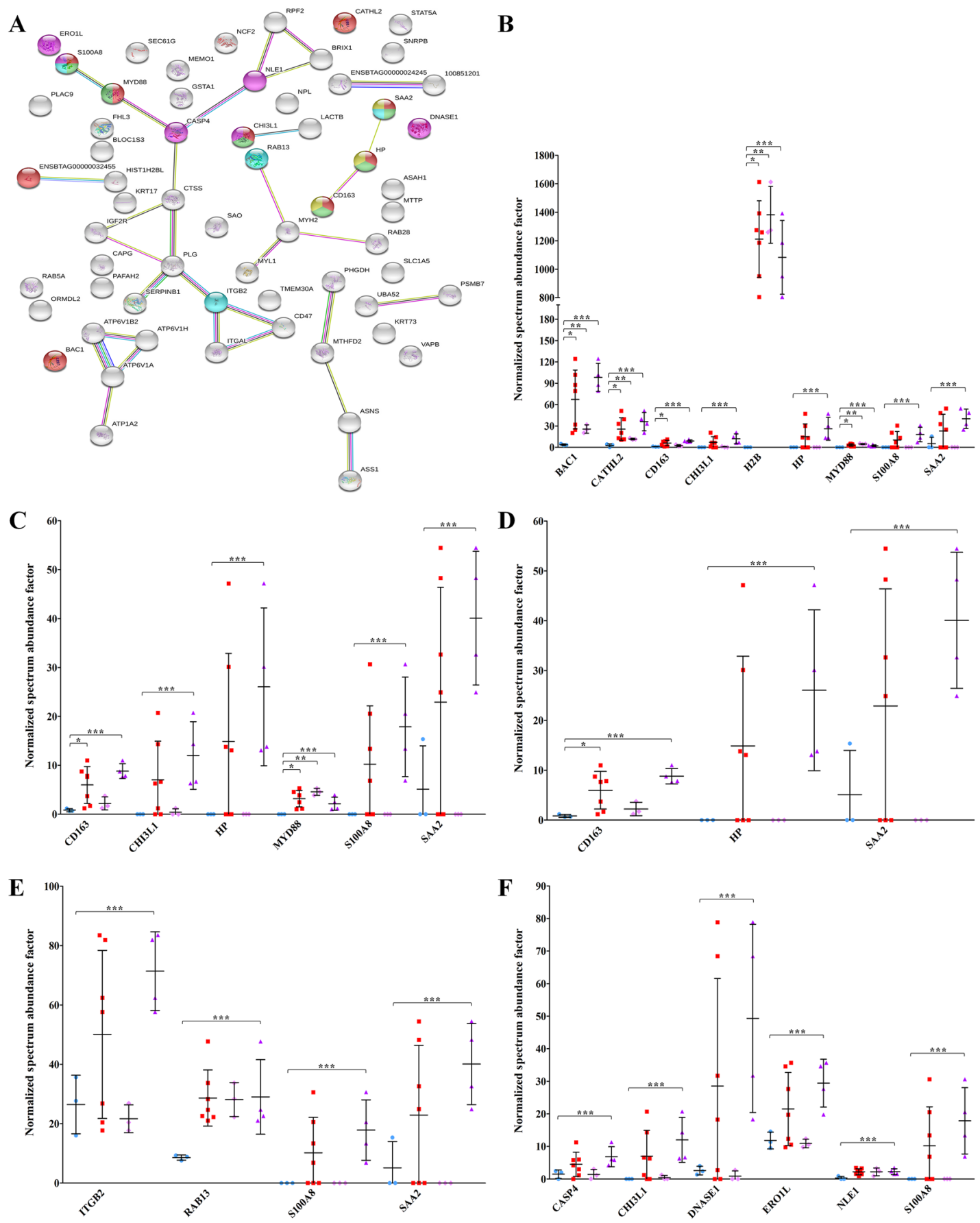

Figure $3 \mathrm{GO}$ analysis (biological process) of proteins significantly increased in PTB vs K. The figure reports the protein network and the proteins included in each category with the respective abundance increases in all PTB samples, in PTB1, and in PTB2, respectively. A Protein network according to STRING. Proteins associated with defense response, inflammatory response, acute phase response, cell chemotaxis, and apoptotic process, are reported in red, green, yellow, sky blue, and fuchsia, respectively. Seven different colored lines link nodes and represent seven types of evidence used in predicting associations. Green lines: neighborhood evidence; red lines: presence of fusion evidence; blue lines: co-occurrence evidence; black lines: co-expression evidence; purple lines: experimental evidence; light blue lines: database evidence; yellow lines: text-mining evidence. Plots show the relative abundances of proteins in defense response $(\mathbf{B})$, in inflammatory response $(\mathbf{C})$, acute phase response $(\mathbf{D})$, cell chemotaxis $(\mathbf{E})$, and apoptotic process (F), indicating values obtained in K (sky blue), PTB (red), PTB1 (pink), and PTB2 (purple) samples. Asterisks indicate statistically significant differences between PTB vs $K(*)$, PTB1 vs $K\left({ }^{* *}\right)$, and PTB2 vs $K\left({ }^{* * *}\right)$ according to the t-test $(p$ value $\leq 0.05$ ). For protein identities corresponding to gene names, please see Table 1. 


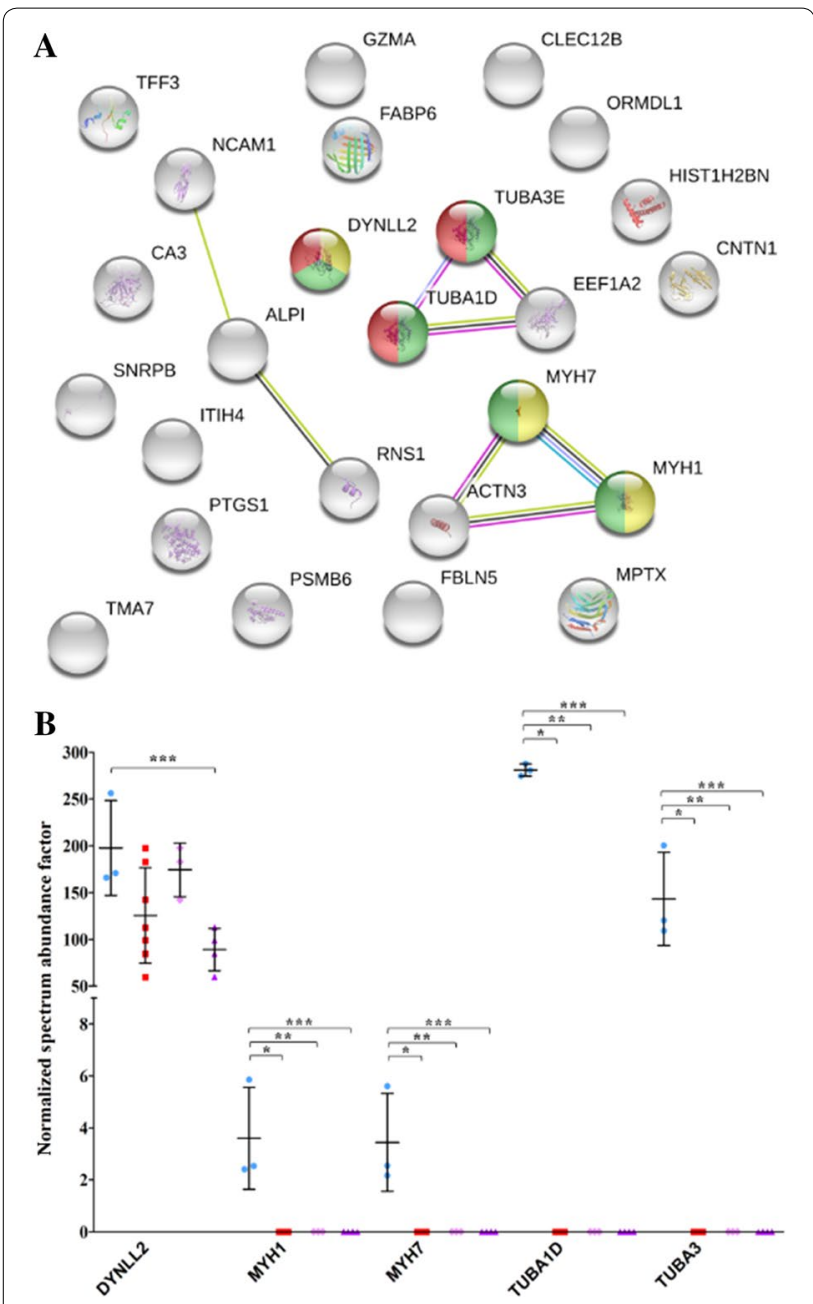

Figure $4 \mathrm{GO}$ analysis (cellular component) of proteins significantly decreased in PTB vs $\mathbf{K}$. The figure reports the protein network and proteins included in the category with the respective abundance decreases in PTB samples, in PTB1, and in PTB2, respectively. A Network obtained by STRING. Proteins associated with cytoskeleton, myosin complex, and microtubule are reported in green, yellow, and red, respectively. Seven different colored lines link nodes and represent seven types of evidence used in predicting associations. Green lines: neighborhood evidence; red lines: presence of fusion evidence; blue lines: co-occurrence evidence; black lines: co-expression evidence; purple lines: experimental evidence; light blue lines: database evidence; yellow lines: text-mining evidence. B Plot illustrating the abundance of proteins in the cytoskeleton network obtained in K (sky blue), PTB (red), PTB1 (pink), and PTB2 (purple) samples. Asterisks indicate statistically significant differences between PTB vs $K\left({ }^{*}\right)$, PTB1 vs $K\left({ }^{* *}\right)$, and PTB2 vs $K\left({ }^{* * *}\right)$ according to the t-test ( $p$ value $\leq 0.05$ ). For protein identities corresponding to gene names, please see Table 1.

lesion severity, fold changes were very high for all subunits and peaked up to a FC of 18.09 for subunit $H$, the specific target for mycobacterium-mediated exclusion $[25,44]$.
Changes in Rab GTPases were also observed. It is known that Rab5 stimulates fusion of early endosomes while Rab7 promotes fusion of mature phagosomes with endosomes and lysosomes [48]. By retaining Rab5, MAP impairs maturation of endosomes into functional mycobactericidal compartments [49]. In line with this, we observed that Rab5 was significantly increased in the PTB2 sample cluster (but not in PTB1). On the other hand, Rab7 was unchanged in both clusters, highlighting the role of Rab5 in the mycobacterial pathogenicity mechanism. The increase seen in Rab13 does also relate to the relevance of the phagocytotic pathway in the host defense from MAP. Tubulins are involved in phagosome maturation, and their massive decrease seen in infected tissues might be related to the impairment of this process in MAP-infected macrophages.

According to GO analysis, most proteins undergoing significant changes in MAP-infected tissues were involved in defense response, inflammatory response and acute phase response. Two isoforms of cathelicidin were increased in all PTB samples, with higher FC values in PTB2 vs PTB1. This result was also in line with our previous study on multibacillary PTB, (FCs of 24.53 for cathelicidin 1 and of 15.79 for cathelicidin 2) [25]. Cathelicidins are well-known antimicrobial peptides with a crucial role in the intracellular killing of mycobacteria in macrophages $[39,50]$. Besides their direct antimicrobial functions, cathelicidins play multiple roles as inflammation mediators [51], and their importance in the innate immune defense of ruminant is highlighted by the unusually large number of genes compared to a single copy in most other mammalians, such as humans and mice [52]. Consistently with the proteomic data, IHC confirmed the absence of cathelicidin in $\mathrm{K}$ tissues and its presence in PTB tissues, with a significantly higher abundance in PTB2 vs PTB1. However, it was not possible to specifically identify the cathelicidin isoform(s) by IHC due to the polyclonal anti-cathelicidin antibodies used. Apparently, DCs were responsible for most of the cathelicidin signal; however, such DC localization might be due to protein capture rather than to protein expression by DCs themselves. Based on studies in humans, cathelicidin (LL-37) is internalized by DCs with subsequent localization primarily in the cytoplasmic compartment and then in the nucleus. This eventually leads to a suppression of their response to toll-like receptor ligands and renders DCs less capable to activate $\mathrm{T}$ lymphocytes. In other words, cathelicidins inhibit DC function [51, 53, 54]. Nevertheless, in human tuberculosis this is inverted by presence of vitamin $\mathrm{D}$, in a finely regulated equilibrium between inhibition and stimulation of cathelicidin production, DC regulation and Th1 differentiation [55]. This is only part of the puzzle governing the combined action 


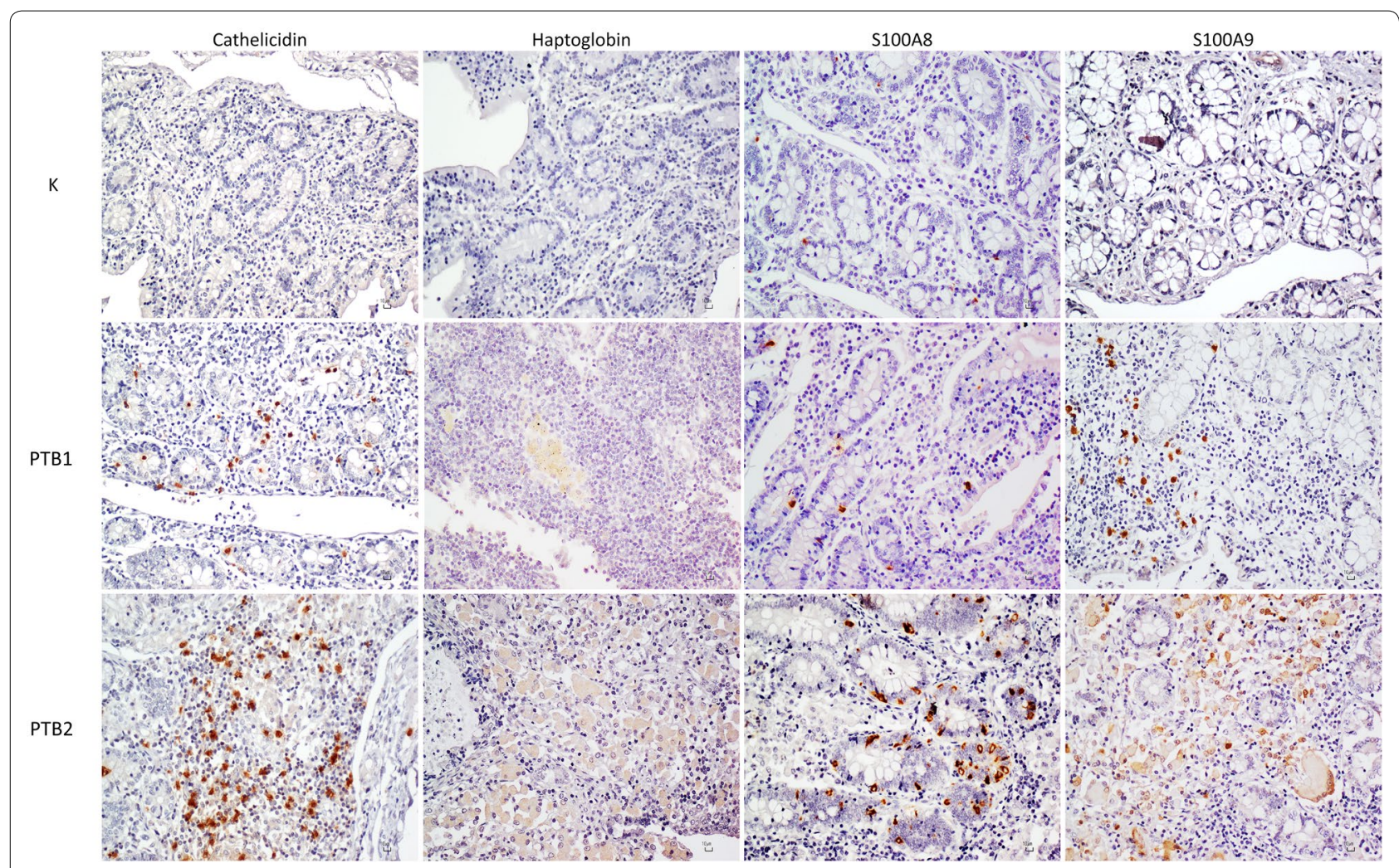

Figure 5 Immunohistochemistry results for selected differential proteins. Representative immunohistochemistry (IHC) images. First row. IHC results for negative control samples $(\mathrm{K}-$ ). Second row. IHC results for PTB1 samples. Third row. IHC results for PTB2 samples.

of genetic background, farming variables and environmental conditions (such as nutritional balance and exposure to light) in resistance of ruminants to mycobacterial diseases, in which the role of cathelicidin regulation of DCs might deserve further investigation.

Several proteins involved in the acute phase response were significantly changed in PTB vs K. Interestingly, haptoglobin, S100A8 and serum amyloid protein A were seen only in PTB2 samples and were not detected in PTB1 or K. This might underscore a potential role for these proteins as markers of disease progression, possibly indicating the activation of an acute inflammatory process when MAP infection is less controlled by the host. Of note, haptoglobin showed the highest increase among all the proteins significant only in PTB2 vs K, with a FC of 13.84. In our previous study on multibacillary MAP infection, haptoglobin showed a FC of 22.93 [25]. Here, upon IHC validation, haptoglobin was abundantly present in tissues of the PTB2 cluster while it was not detected in tissues of the PTB1 cluster. Notably, haptoglobin-positive cells appeared to be almost exclusively macrophages. This might be related to its scavenging functions; in fact, haptoglobin captures hemoglobin by forming a complex that is promptly internalized by macrophages. Its endocytosis and targeting to the lysosome are mediated by the macrophage receptor CD163 (scavenger receptor cysteine-rich type 1 protein M130) [56]. Consistently with this observation, CD163 was significantly increased only in the PTB2 Cluster. Once again, the observed increase in protein abundance within the affected tissue is probably due to selective capture, rather than increased expression, by the cell. An increase in the CD163 receptor has been observed also in ileal tissues of cattle infected by MAP [57]. It would be interesting to investigate how an increased availability of iron within the macrophage phagosomes is reflected on MAP pathogenicity.

S100A8 plays a prominent role in the regulation of inflammation and immune response. It can induce neutrophil chemotaxis and adhesion, and it is predominantly found as the calprotectin heterodimer in association with S100A9, with a wide plethora of intra- and extracellular functions [58]. Fecal calprotectin is currently used in human medicine to differentiate organic from functional bowel disorders [42]. Upon IHC validation, S100A8 was detected in all PTB samples, but few, scattered positive cells were also present in $\mathrm{K}$ tissues. The number of S100A8-positive cells was about three times higher in PTB2 than PTB1. In consideration of its known association with S100A9, it was surprising that the latter protein 
was not detected by proteomics in any of the experimental samples. However, S100A9 was readily detected by IHC in all PTB samples. The number of S100A9-positive cells was higher than that of S100A8-positive cells, and the cell type was also different. A possible explanation is that S100 proteins can also exist as homodimers [58], and a differential expression or a selective capture of S100A9 by a specific cell type might be occurring.

Another protein significantly increased in PTB was protein transport protein Sec61 (SEC61). As recently discovered, SEC61 is present in antigen-containing endosomes of DCs after stimulation with microbial substances and is essential for endosome-to-cytosol translocation and for antigen cross-presentation to $\mathrm{T}$ cells [59]. This pathway enables DCs to present extracellular antigens onto MHC I molecules, thereby stimulating naive cytotoxic CD8+ $\mathrm{T}$ cells into activated cytotoxic CD8+ T cells. This is only part of the complex mechanisms responsible for the predominance of the Th1 or Th2 response, a crucial step in the control of mycobacterial infections.

$\mathrm{H} 2 \mathrm{~B}$ was the most increased protein in all PTB samples. This might relate to the well-known antimicrobial role of histones. On the other hand, ubiquitin was the second highest protein, and this might indicate the occurrence of an extensive histone ubiquitination [60]. Nevertheless, it should be reminded that shotgun proteomics results as analyzed and presented here can only provide information on relative protein abundance. These data can give useful hints on protein networks and pathways activated upon infection, but indications on protein structure, protein interactions or post-translational modifications need dedicated experimental investigations or data analysis algorithms.

Adding to proteins increased in PTB2, proteins significantly increased only in samples of the PTB1 cluster (such as fatty acid-binding protein, glutathione S-transferase, Na/K-transporting ATPase, argininosuccinate synthase) or detected only in the PTB1 cluster (such as Rab-28), could also be worth investigating further; these proteins might represent potential indicators of a better ability to contrast disease and, should this be demonstrated, have potential as targets in genetic selection for resistance to mycobacterial diseases.

Finally, as anticipated, it should be reminded that this study was carried out on a limited number of animals due to methodological constraints. Stringent statistic procedures were applied in differential proteomic analysis and IHC validation confirmed the main study findings, but observations such as the relationship of PTB1 and PTB2 clusters with type 2 and type 3 a lesions or any hypothesis on their connection with disease progression or increased pathogenicity and associated pathways will need to be investigated further with studies on a larger, well-characterized sample cohort by means of higher throughput techniques, such as IHC or other molecular tests, for a thorough validation on the entire range of lesions including also multibacillary cases. It should also be highlighted that low-abundance mediators such as cytokines were not identified in this study, as in most shotgun proteomics studies. However, these have been investigated in detail by other authors in paucibacillary PTB $[17,20,61,62]$.

In conclusion, this work provided the first detailed proteomic characterization of paucibacillary MAP-infected sheep ileal tissues in comparison to MAP-free tissues. The differential proteomic analysis combined with immunohistochemical validation highlighted several changes occurring in PTB tissues and provided novel molecular information on the distinct levels of tissue involvement that can be found within the asymptomatic, paucibacillary condition. Adding to useful insights into disease processes and pathways, we identified several proteins that are absent in healthy tissues and are present in MAPinfected tissues, with differences in abundance levels or localization possibly reflecting different degrees of lesion severity. These host protein markers can assist future investigations aimed at understanding PTB evolution and progression, either with classical post-mortem analysis of tissues or, hopefully, by enabling the development of immunoassay tools for their in vivo detection in feces.

\section{Additional files}

Additional file 1. Histopathological grading scores and histopathological features of the PTB1 and PTB2 cluster samples. The file describes in detail: i) the grading scores assigned to all sheep tissue samples considered in this study; ii) Hematoxylin-Eosin and Ziehl-Neelsen stained panoramic and detailed views of PTB1 and PTB2 tissues illustrating their main features.

Additional file 2. Number of identified proteins, peptides, PSMs and Search Inputs in $\mathrm{K}$ and $\mathrm{P}$ samples. The file contains a table with the detailed report of all the results obtained for each tissue sample, and the average values measured in $\mathrm{K}$ and $\mathrm{P}$ samples.

Additional file 3. Protein identification details and differential proteomic results based on label-free quantitation. Excel file reporting: the list of all proteins identified in each sample with the detailed data for coverage, proteins, unique peptides, and PSMs; the average NSAF value of each sheep protein in all experimental samples; the average NSAF value of each MAP protein in all experimental samples; and the complete list of all differential proteins detected in PTB vs K, PTB1 vs K, and PTB2 vs K, with the respective $R_{s c}, F C$, beta-binomial $p$ value, and beta-binomial $p$ value after Benjamini-Hochberg correction.

Additional file 4. Results of KEGG enrichment analysis and GO analysis. Excel file reporting the detailed results obtained with STRING for KEGG enrichment analysis, Biological process, Molecular function and Cellular component.

Additional file 5. Column statistics of IHC results. Table reporting the mean, standard deviation (SD), median, interquartile range (IQR), minimum and maximum (Min-Max) value of the number of cells measured in a $200 \times$ magnification field of the distal ileum in PTB1 and PTB2 sheep. 


\section{Competing interests}

The authors declare that they have no competing interests.

\section{Authors' contributions}

Design of study and experiments: SP, TC, SU, SR, MFA. Carrying out of laboratory and field activities: SP, TC, CC, YP, SR. Analysis of results and interpretation of data: SP, TC, SR, MFA. Manuscript drafting: SP, TC, MFA. Manuscript revision: CC, DP, SR, SU, MFA. All authors read and approved the final manuscript.

\section{Acknowledgements}

The authors wish to thank the farm veterinarian Francesco Salis for his valuable contribution to this work.

\section{Author details}

1 Porto Conte Ricerche, SP 55 Porto Conte/Capo Caccia, Km 8.400, Loc. Tramariglio, 07041 Alghero, Italy. ${ }^{2}$ Dipartimento di Medicina Veterinaria, Università degli Studi di Sassari, Via Vienna 2, 07100 Sassari, Italy. ${ }^{3}$ Dipartimento di Scienze Biomediche, Università degli Studi di Sassari, Viale S. Pietro 43/B, 07100 Sassari, Italy. ${ }^{4}$ Dipartimento di Medicina Veterinaria, Università degli Studi di Milano, Via Celoria 10, 20133 Milan, Italy.

\section{Ethics approval and consent to participate}

The farmer was informed of the study and intestinal samples were collected at the slaughterhouse during routine procedures. Animals were not sacrificed for the purposes of the study but as a result of the food production procedures. The study did not influence in any way the killing of animals.

\section{Funding}

The study was financially supported by Sardegna Ricerche with the Grant Art. 26 2013, and with funds granted by the University of Sassari. The funding bodies had no role in the design of the study and collection, analysis, and interpretation of data and in writing the manuscript.

\section{Publisher's Note}

Springer Nature remains neutral with regard to jurisdictional claims in published maps and institutional affiliations.

Received: 7 September 2018 Accepted: 13 November 2018 Published online: 04 December 2018

\section{References}

1. Hines SA, Buergelt CD, Wilson JH, Bliss EL (1987) Disseminated Mycobacterium paratuberculosis infection in a cow. J Am Vet Med Assoc 190:681-683

2. Windsor PA (2015) Paratuberculosis in sheep and goats. Vet Microbiol 181:161-169

3. Carrigan MJ, Seaman JT (1990) The pathology of Johne's disease in sheep. Aust Vet J 67:47-50

4. Corpa JM, Garrido J, García Marín JF, Pérez V (2000) Classification of lesions observed in natural cases of paratuberculosis in goats. J Comp Pathol 122:255-265

5. McGregor H, Abbott KA, Whittington RJ (2015) Effects of Mycobacterium avium subsp. paratuberculosis infection on serum biochemistry, body weight and wool growth in Merino sheep: a longitudinal study. Small Rumin Res 125:146-153

6. Bush RD, Windsor PA, Toribio JA (2006) Losses of adult sheep due to ovine Johne's disease in 12 infected flocks over a 3-year period. Aust Vet J 84:246-253

7. Millar D, Ford J, Sanderson J, Withey S, Tizard M, Doran T, Hermon-Taylor J (1996) IS900 PCR to detect Mycobacterium paratuberculosis in retail supplies of whole pasteurized cows' milk in England and Wales. Appl Environ Microbiol 62:3446-3452

8. Grant IR, Ball HJ, Neill SD, Rowe MT (1996) Inactivation of Mycobacterium paratuberculosis in cows' milk at pasteurization temperatures. Appl Environ Microbiol 62:631-636

9. Monif GRG (2016) The Mycobacterium avium subspecies paratuberculosis dilemma. Biol Med (Aligarh) 8:270
10. Arsenault RJ, Maattanen P, Daigle J, Potter A, Griebel P, Napper S (2014) From mouth to macrophage: mechanisms of innate immune subversion by Mycobacterium avium subsp. paratuberculosis. Vet Res 45:54

11. Chiodini RJ, Van Kruiningen HJ, Merkal RS (1984) Ruminant paratuberculosis (Johne's disease): the current status and future prospects. Cornell Vet 74:218-262

12. Stabel JR (2000) Transitions in immune responses to Mycobacterium paratuberculosis. Vet Microbiol 77:465-473

13. Sweeney RW (1996) Transmission of paratuberculosis. Vet Clin North Am Food Anim Pract 12:305-312

14. Lambeth $C$, Reddacliff LA, Windsor P, Abbott KA, McGregor H, Whittington RJ (2004) Intrauterine and transmammary transmission of Mycobacterium avium subsp. paratuberculosis in sheep. Aust Vet J $82 \cdot 504-508$

15. Nebbia P, Robino P, Zoppi S, De Meneghi D (2006) Detection and excretion pattern of Mycobacterium avium subspecies paratuberculosis in milk of asymptomatic sheep and goats by nested-PCR. Small Rumin Res 66:116-120

16. Ponnusamy D, Periasamy S, Tripathi BN, Pal A (2013) Mycobacterium avium subsp. paratuberculosis invades through $\mathrm{M}$ cells and enterocytes across ileal and jejunal mucosa of lambs. Res Vet Sci 94:306-312

17. Gillan S, O'Brien R, Hughes AD, Griffin JFT (2010) Identification of immune parameters to differentiate disease states among sheep infected with Mycobacterium avium subsp. paratuberculosis. Clin Vaccine Immunol 17:108-117

18. Begara-Mcgorum I, Wildblood LA, Clarke CJ, Connor KM, Stevenson K, Mclnnes CJ, Sharp JM, Jones DG (1998) Early immunopathological events in experimental ovine paratuberculosis. Vet Immunol Immunopathol 63:265-287

19. Sergeant ESG, Marshall DJ, Eamens GJ, Kearns C, Whittington RJ (2003) Evaluation of an absorbed ELISA and an agar-gel immuno-diffusion test for ovine paratuberculosis in sheep in Australia. Prev Vet Med 61:235-248

20. Marquetoux N, Mitchell R, Ridler A, Heuer C, Wilson P (2018) A synthesis of the patho-physiology of Mycobacterium avium subspecies paratuberculosis infection in sheep to inform mathematical modelling of ovine paratuberculosis. Vet Res 49:27

21. Whittington RJ, Begg DJ, de Silva K, Purdie AC, Dhand NK, Plain KM (2017) Case definition terminology for paratuberculosis (Johne's disease). BMC Vet Res 13:328

22. Pérez V, García Marín JF, Badiola JJ (1996) Description and classification of different types of lesion associated with natural paratuberculosis infection in sheep. J Comp Pathol 114:107-122

23. Kurade NP, Tripathi BN, Rajukumar K, Parihar NS (2004) Sequential development of histologic lesions and their relationship with bacterial isolation, fecal shedding, and immune responses during progressive stages of experimental infection of lambs with Mycobacterium avium subsp. paratuberculosis. Vet Pathol 41:378-387

24. Hailat NQ, Hananeh W, Metekia AS, Stabel JR, Al-Majali A, Lafi S (2010) Pathology of subclinical paratuberculosis (Johne's Disease) in Awassi sheep with reference to its occurrence in Jordan. Vet Med (Praha) 55:590-602

25. Pisanu S, Cubeddu T, Uzzau S, Rocca S, Addis MF (2017) Proteomic changes in the ileum of sheep infected with Mycobacterium avium subspecies paratuberculosis. Vet J 219:1-3

26. Collins DM, De Zoete M, Cavaignac SM (2002) Mycobacterium avium subsp. paratuberculosis strains from cattle and sheep can be distinguished by a PCR test based on a novel DNA sequence difference. J Clin Microbiol 40:4760-4762

27. Pisanu S, Biosa G, Carcangiu L, Uzzau S, Pagnozzi D (2018) Comparative evaluation of seven commercial products for human serum enrichment/ depletion by shotgun proteomics. Talanta 185:213-220

28. The M, MacCoss MJ, Noble WS, Käll L (2016) Fast and accurate protein false discovery rates on large-scale proteomics data sets with Percolator 3.0. J Am Soc Mass Spectrom 27:1719-1727

29. Käll L, Canterbury JD, Weston J, Noble WS, MacCoss MJ (2007) Semisupervised learning for peptide identification from shotgun proteomics datasets. Nat Methods 4:923-925

30. The M, Tasnim A, Käll L (2016) How to talk about protein-level false discovery rates in shotgun proteomics. Proteomics 16:2461-2469 
31. Old WM, Meyer-Arendt K, Aveline-Wolf L, Pierce KG, Mendoza A, Sevinski JR, Resing KS, Ahn NG (2005) Comparison of label-free methods for quantifying human proteins by shotgun proteomics. Mol Cell Proteomics 4:1487-1502

32. Pagnozzi D, Biosa G, Addis MF, Mastrandrea S, Masala G, Uzzau S (2014) An easy and efficient method for native and immunoreactive Echinococcus granulosus antigen 5 enrichment from hydatid cyst fluid. PLoS One 9:e104962

33. Zybailov B, Mosley AL, Sardiu ME, Coleman MK, Florens L, Washburn MP (2006) Statistical analysis of membrane proteome expression changes in Saccharomyces cerevisiae. J Proteome Res 5:2339-2347

34. Tanca A, Pagnozzi D, Burrai G, Polinas M, Uzzau S, Antuofermo E, Addis MF (2012) Comparability of differential proteomics data generated from paired archival fresh-frozen and formalin-fixed samples by GeLC-MS/MS and spectral counting. J Proteomics 77:561-576

35. Pham TV, Piersma SR, Warmoes M, Jimenez CR (2010) On the beta-binomial model for analysis of spectral count data in label-free tandem mass spectrometry-based proteomics. Bioinformatics 26:363-369

36. Kammers K, Cole RN, Tiengwe C, Ruczinski I (2015) Detecting significant changes in protein abundance. EuPA Open Proteomics 7:11-19

37. Szklarczyk D, Franceschini A, Wyder S, Forslund K, Heller D, Huerta-Cepas J, Simonovic M, Roth A, Santos A, Tsafou KP, Kuhn M, Bork P, Jensen LJ, von Mering C (2015) STRING v10: protein-protein interaction networks, integrated over the tree of life. Nucleic Acids Res 43:D447-D452

38. Cubeddu T, Cacciotto C, Pisanu S, Tedde V, Alberti A, Pittau M, Dore S, Cannas A, Uzzau S, Rocca S, Addis MF (2017) Cathelicidin production and release by mammary epithelial cells during infectious mastitis. Vet Immunol Immunopathol 189:66-70

39. Sonawane A, Santos JC, Mishra BB, Jena P, Progida C, Sorensen OE, Gallo R, Appelberg R, Griffiths G (2011) Cathelicidin is involved in the intracellular killing of mycobacteria in macrophages. Cell Microbiol 13:1601-1617

40. Zanetti M (2005) The role of cathelicidins in the innate host defenses of mammals. Curr Issues Mol Biol 7:179-196

41. Gill N, Wlodarska M, Finlay BB (2011) Roadblocks in the gut: barriers to enteric infection. Cell Microbiol 13:660-669

42. Burri E, Beglinger C (2014) The use of fecal calprotectin as a biomarker in gastrointestinal disease. Expert Rev Gastroenterol Hepatol 8:197-210

43. Chromek M, Slamová Z, Bergman P, Kovács L, Podracká L, Ehrén I, Hökfelt T, Gudmundsson GH, Gallo RL, Agerberth B, Brauner A (2006) The antimicrobial peptide cathelicidin protects the urinary tract against invasive bacterial infection. Nat Med 12:636-641

44. Wong D, Bach H, Sun J, Hmama Z, Av-Gay Y (2011) Mycobacterium tuberculosis protein tyrosine phosphatase (PtpA) excludes host vacuolar$\mathrm{H}+$-ATPase to inhibit phagosome acidification. Proc Natl Acad Sci U S A 108:19371-19376

45. Weiss DJ, Evanson OA, Moritz A, Deng MQ, Abrahamsen MS (2002) Differential responses of bovine macrophages to Mycobacterium avium subsp. paratuberculosis and Mycobacterium avium subsp. avium. Infect Immun 70:5556-5561

46. Murphy JT, Sommer S, Kabara EA, Verman N, Kuelbs MA, Saama P, Halgren R, Coussens PM (2006) Gene expression profiling of monocyte-derived macrophages following infection with Mycobacterium avium subspecies avium and Mycobacterium avium subspecies paratuberculosis. Physiol Genomics 28:67-75

47. Weiss DJ, Evanson OA, de Souza C, Abrahamsen MS (2005) A critical role of interleukin-10 in the response of bovine macrophages to infection by Mycobacterium avium subsp. paratuberculosis. Am J Vet Res 66:721-726

48. Chua CEL, Gan BQ, Tang BL (2011) Involvement of members of the Rab family and related small GTPases in autophagosome formation and maturation. Cell Mol Life Sci 68:3349-3358

49. Fratti RA, Backer JM, Gruenberg J, Corvera S, Deretic V (2001) Role of phosphatidylinositol 3-kinase and Rab5 effectors in phagosomal biogenesis and mycobacterial phagosome maturation arrest. J Cell Biol 154:631-644
50. Liu PT, Stenger S, Tang DH, Modlin RL (2007) Cutting edge: vitamin D-mediated human antimicrobial activity against Mycobacterium tuberculosis is dependent on the induction of cathelicidin. J Immunol 179:2060-2063

51. Agier J, Efenberger M, Brzezińska-Blaszczyk E (2015) Cathelicidin impact on inflammatory cells. Cent Eur J Immunol 40:225-235

52. Bovine Genome Sequencing and Analysis Consortium, Elsik CG, Tellam RL, Worley KC, Gibbs RA, Muzny DM, Weinstock GM, Adelson DL, Eichler EE, Elnitski L, Guigó R, Hamernik DL, Kappes SM, Lewin HA, Lynn DJ, Nicholas FW, Reymond A, Rijnkels M, Skow LC, Zdobnov EM, Schook L, Womack J, Alioto T, Antonarakis SE, Astashyn A, Chapple CE, Chen HC, Chrast J, Câmara F, Ermolaeva O, Henrichsen CN et al (2009) The genome sequence of taurine cattle: a window to ruminant biology and evolution. Science 324:522-528

53. Bandholtz L, Ekman GJ, Vilhelmsson M, Buentke E, Agerberth B, Scheynius A, Gudmundsson GH (2006) Antimicrobial peptide LL-37 internalized by immature human dendritic cells alters their phenotype. Scand I Immunol 63:410-419

54. Kandler K, Shaykhiev R, Kleemann P, Klescz F, Lohoff M, Vogelmeier C, Bals R (2006) The anti-microbial peptide LL-37 inhibits the activation of dendritic cells by TLR ligands. Int Immunol 18:1729-1736

55. Rode AKO, Kongsbak M, Hansen MM, Lopez DV, Levring TB, Woetmann A, Ødum N, Bonefeld CM, Geisler C (2017) Vitamin D counteracts Mycobacterium tuberculosis-induced cathelicidin downregulation in dendritic cells and allows Th1 differentiation and IFNy secretion. Front Immunol 8:656

56. Graversen JH, Madsen M, Moestrup SK (2002) CD163: a signal receptor scavenging haptoglobin-hemoglobin complexes from plasma. Int J Biochem Cell Biol 34:309-314

57. Fernández M, Benavides J, Castaño P, Elguezabal N, Fuertes M, Muñoz M, Royo M, Ferreras MC, Pérez V (2017) Macrophage subsets within granulomatous intestinal lesions in bovine paratuberculosis. Vet Pathol 54:82-93

58. Ryckman C, Vandal K, Rouleau P, Talbot M, Tessier PA (2003) Proinflammatory activities of S100: proteins S100A8, S100A9, and S100A8/A9 induce neutrophil chemotaxis and adhesion. J Immunol 170:3233-3242

59. Zehner M, Marschall AL, Bos E, Schloetel JG, Kreer C, Fehrenschild D, Limmer A, Ossendorp F, Lang T, Koster AJ, Dübel S, Burgdorf S (2015) The translocon protein Sec61 mediates antigen transport from endosomes in the cytosol for cross-presentation to CD8+T cells. Immunity 42:850-863

60. Chandrasekharan MB, Huang F, Sun ZW (2010) Histone H2B ubiquitination and beyond: regulation of nucleosome stability, chromatin dynamics and the trans-histone $\mathrm{H} 3$ methylation. Epigenetics 5:460-468

61. Smeed JA, Watkins CA, Rhind SM, Hopkins J (2007) Differential cytokine gene expression profiles in the three pathological forms of sheep paratuberculosis. BMC Vet Res 3:18

62. de Silva K, Plain K, Purdie A, Begg D, Whittington R (2018) Defining resilience to mycobacterial disease: characteristics of survivors of ovine paratuberculosis. Vet Immunol Immunopathol 195:56-64

Ready to submit your research? Choose BMC and benefit from:

- fast, convenient online submission

- thorough peer review by experienced researchers in your field

- rapid publication on acceptance

- support for research data, including large and complex data types

- gold Open Access which fosters wider collaboration and increased citations

- maximum visibility for your research: over $100 \mathrm{M}$ website views per year

At BMC, research is always in progress.

Learn more biomedcentral.com/submissions 